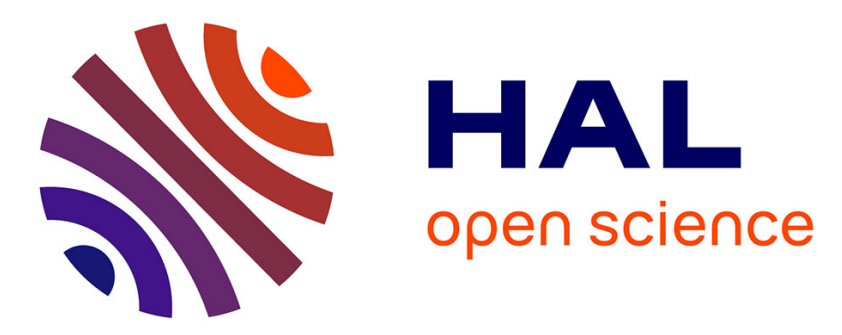

\title{
Normalization strategies for microRNA profiling experiments: a 'normal' way to a hidden layer of complexity?
}

\author{
Swanhild U. Meyer, Michael W. Pfaffl, Susanne E. Ulbrich
}

\section{- To cite this version:}

Swanhild U. Meyer, Michael W. Pfaffl, Susanne E. Ulbrich. Normalization strategies for microRNA profiling experiments: a 'normal' way to a hidden layer of complexity?. Biotechnology Letters, 2010, 32 (12), pp.1777-1788. 10.1007/s10529-010-0380-z . hal-00614505

\section{HAL Id: hal-00614505 \\ https://hal.science/hal-00614505}

Submitted on 12 Aug 2011

HAL is a multi-disciplinary open access archive for the deposit and dissemination of scientific research documents, whether they are published or not. The documents may come from teaching and research institutions in France or abroad, or from public or private research centers.
L'archive ouverte pluridisciplinaire HAL, est destinée au dépôt et à la diffusion de documents scientifiques de niveau recherche, publiés ou non, émanant des établissements d'enseignement et de recherche français ou étrangers, des laboratoires publics ou privés. 
Section: Review

Normalization strategies for microRNA profiling experiments a 'normal' way to a hidden layer of complexity?

Swanhild U. Meyer*, Michael W. Pfaffl, Susanne E. Ulbrich

Physiology Weihenstephan, ZIEL Research Center for Nutrition and Food Sciences

Technische Universität München, Weihenstephaner Berg 3, D-85354 Freising Germany

Invited review

${ }^{*}$ Correspondence to:

Swanhild U. Meyer

Physiology Weihenstephan, ZIEL Research Center for Nutrition and Food Sciences,

Technische Universität München, Weihenstephaner Berg 3, D-85354 Freising Germany

Tel.: $\quad+49-8161-715552$

Fax: $\quad+49-8161-714204$

E-mail: meyers@wzw.tum.de 


\section{Abstract}

MicroRNA (miRNA) profiling is a first important step in elucidating miRNA functions. Real time quantitative PCR (RT-qPCR) and microarray hybridization approaches as well as ultra high throughput sequencing of miRNAs (small RNA-seq) are popular and widely used profiling methods. All of these profiling approaches face significant introduction of bias. Normalization, often an underestimated aspect of data processing, can minimize systematic technical or experimental variation and thus has significant impact on the detection of differentially expressed miRNAs. At present, there is no consensus normalization method for any of the three miRNA profiling approach. Several normalization techniques are currently in use, of which some are similar to mRNA profiling normalization methods, while others are specifically modified or developed for miRNA data. The characteristic nature of miRNA molecules, their composition and the resulting data distribution of profiling experiments challenges the selection of adequate normalization techniques. Based on miRNA profiling studies and comparative studies on normalization methods and their performances, this review provides a critical overview of commonly used and newly developed normalization methods for miRNA RT-qPCR, miRNA hybridization microarray, and small RNA-seq datasets. Emphasis is laid on the complexity, the importance and the potential for further optimization of normalization techniques for miRNA profiling datasets.

Key words: microarray, microRNA, normalization, profiling, real time quantitative PCR, ultra high throughput sequencing 


\section{Introduction}

The importance of microRNAs (miRNAs), a class of small RNAs mediating posttranscriptional gene regulation, has been shown in several cellular processes as well as in different metabolic and pathologic conditions. Predominantly, miRNAs repress gene expression by binding of target mRNAs and formation of the RNA-induced silencing complex (RISC) (reviewed in Carthew and Sontheimer 2009). Multiple mechanisms by which miRNAs cause translational repression at the translation initiation step or at post-initiation steps as well as mRNA decay through deadenylation have been reported (reviewed in Fabian et al. 2010). Moreover, miRNAs activate rather than repress translation in quiescent cells (Vasudevan et al. 2007). However, miRNA-mediated activation of translation is probably not a general mechanism in nonproliferating cells (Fabian et al. 2010).

The expression, regulation and function of miRNA are addressed in an increasing number of studies. To date, more than 10,500 miRNAs from 115 species are registered in the miRSanger Base (Release 14) (http://www.mirbase.org) (Griffiths-Jones et al. 2008) and according to bioinformatic predictions, this number is expected to increase further (Sheng et al. 2007). The specific function of individual miRNAs is only partly known and in most cases not fully understood. High throughput miRNA profiling is a first important step in characterizing specific miRNA signatures and thus, in unravelling the regulatory functions of this species of small RNAs.

Understanding miRNA functions implies great potential for the application in the field of biotechnology as well as diagnostic and therapeutic approaches. For example, miRNAs have been shown to be key regulators for the induction or maintenance of cell fate in plants (Carlsbecker et al. 2010), mammalian cells (Cardinali et al. 2009), cancer (Kim et al. 2010), and stem cells (Gunaratne 2009; Gangaraju and Lin 2009). Furthermore, miRNAs can serve as biomarkers (Baker 2010). Experimental evidence demonstrates that correction of specific miRNA alterations using miRNA mimics or antagomirs can reverse the phenotype in 
cancerous cells (Wang and Wu 2009). Thus, miRNA-based therapeutic interventions as well as diagnostics are being developed (Pfeifer and Lehmann 2010).

In addition, miRNA expression profiles may be more accurate than mRNA expression profiles in disease classification (Lu et al. 2005). Accordingly, numerous methods have been established to identify and globally quantify small RNAs (Li and Ruan 2009; Yin et al. 2008; Benes and Castoldi 2010; Kong et al. 2009). Real-time quantitative PCR (RT-qPCR) was optimized to not only perform single reverse transcription and PCR amplification experiments but also for a large number of miRNAs in parallel by multi- or megaplexing (Chen et al. 2005; Benes and Castoldi 2010). Currently, RT-qPCR is the method of choice for validation of miRNA profiling results from other holistic platforms. Hybridization based quantitative miRNA profiling by microarrays (Yin et al. 2008; Li and Ruan 2009) has become a widely used and popular method as e.g. a valuable tool for biomarker and therapeutic target identification and functional prediction of miRNAs by correlating miRNA expression patterns to corresponding mRNA (Jayaswal et al. 2009; Manakov et al. 2009) and protein profiles (lliopoulos et al. 2008). MiRNA profiling strategies based on deep sequencing (reviewed in Wang et al. 2009; Linsen et al. 2009) allow the de novo identification as well as the relative quantification of miRNAs and are essential for getting a holistic picture of small RNA signatures. Each miRNA profiling strategy faces unique challenges. Specific strengths and entailed consequences are of distinct importance to consider depending on the nature of the research context (Table 1). The analysis of microRNA expression faces several challenges. Both the short length and the heterogeneous GC content of miRNAs result in large impede intervals of melting temperatures complicating optimized probe or primer design (Benes and Castoldi 2010; Yin et al. 2008). Extended loop probes (Wang et al. 2007), stem-loop primer (Chen et al. 2005), or the incorporation of modified nucleotides, e.g. locked nucleic acids (Castoldi et al. 2008) or 2'-O-(2-methoxyethyl)-derivatives (Beuvink et al. 2007) have been used for normalization of melting temperatures. Furthermore, as the mature form of the miRNA is derived by processing of genome encoded hairpin-shaped precursors, the sequence of interest is not only present in the mature miRNA but also in the primary transcript (pri-miRNA) and the 
precursor miRNA (pre-miRNA). Finally, miRNAs within the same family may differ by a single nucleotide only (reviewed in Benes and Castoldi 2010). Potential cross-hybridization or cross-sequencing specificity issues may complicate the discrimination of the expression of closely related miRNAs (Willenbrock et al. 2009). In general, similarly to mRNA expression analysis, miRNA quantification depends on high quality RNA (Becker et al. 2010).

Thus, in addition to adequate experimental design, data analysis of miRNA profiling experiments needs to account for the specific physicochemical nature of miRNAs, their expression pattern, and the properties of the analytical tools used such as technical variation. One particularly important aspect of preprocessing of miRNA profiling data is to apply an optimal normalization method. The purpose of data normalization is to minimize the effects of systematic experimental bias and technical variations. Therefore, normalization is a prerequisite for getting true biological changes and allowing biologically meaningful comparisons to be made. Several studies pointed out that selection of the data preprocessing method can have great impact on the resulting data outcome (Lopez-Romero et al. 2010; Hua et al. 2008; Pradervand et al. 2009; Risso et al. 2009; Sarkar et al. 2009) such as identification of differentially expressed miRNAs and data interpretation. Thus, inappropriate normalization of the data can lead to incorrect conclusions. Rigorous normalization of miRNA data may even be more critical than that of other RNA functional classes since relatively small changes in miRNA expression may be biologically and clinically significant (Peltier and Latham 2008, Chang et al. 2010).

Various normalization techniques have been developed in the context of mRNA profiling methods. These normalization approaches can in part be directly applied to miRNA data as well. However, some normalization methods have been challenged and adapted to the specific nature of miRNA profiling experiments. At present, there is no consensus normalization for either an RT-qPCR, hybridization microarray, or deep sequencing based miRNA profiling approach. 


\section{Data processing of miRNA profiling experiments}

Prior to normalization, data preprocessing of miRNA profiling experiments includes platform and vendor specific steps, such as e.g. baseline adjustment and threshold setting for RTqPCR analyses, background correction for microarray technology, or filtering for small RNAsequence data. Following these very first steps of raw data preprocessing the experimenter needs to choose the optimal normalization strategy to correct for systematic and technical variation enabling a better estimation of the biological variation.

\section{Normalization approaches for miRNA RT-qPCR}

The guidelines for quality control and standardization of RT-qPCR experiments imply the use of the optimal normalization method (Bustin 2010; Bustin et al. 2009). This is not only important for mRNA, but as well for miRNA quantification. Normalization of RT-qPCR miRNA profiling data is needed as in addition to reflecting miRNA levels, signal intensities may also depend on reverse transcription and PCR reaction efficiencies. Normalized miRNA RT-qPCR profiling data is widely used for independent evaluation of the goodness of miRNA microarray normalization strategies (Sarkar et al. 2009; Pradervand et al. 2009; Sato et al. 2009; Hua et al. 2008) and validation of microarray or small RNA-seq results (Git et al. 2010). RT-qPCR is generally accepted as gold standard for microRNA measurement (Sato et al. 2009; Hua et al. 2008) though this view has been recently challenged (Git et al. 2010).

Normalization based on predefined invariant endogenous controls, reference miRNAs (Peltier and Latham 2008) or other small non-coding RNAs such as small nuclear, small nucleolar RNA (summarized in Table 2) or 5s rRNA, is a commonly used approach in miRNA RT-qPCR profiling data analysis (Benes and Castoldi 2010; Pradervand et al. 2009; Mestdagh et al. 2009). However, the use of small non-coding RNAs other than miRNAs does 
not mirror the physicochemical properties of miRNA molecules and it has been argued that it is best to normalize genes with reference genes belonging to the same RNA class (Vandesompele et al. 2002). Using non-miRNA reference genes for qPCR normalization is not advisable when the overall abundance of miRNA varies, e.g., in experiments affecting the miRNA processing machinery, or in comparisons involving multiple tissues or combinations of tissues and cell lines (Git et al. 2010). Selection of invariant miRNAs identified by algorithms specifically developed for reference gene evaluation and selection e.g. based on reference gene ranking and stepwise elimination of the least stable gene (Vandesompele et al. 2002), or repeated pairwise correlation and regression analysis (Pfaffl et al. 2004), or statistical linear mixed-effects modelling (Andersen et al. 2004) of the respective experimental data was superior over small non-coding RNA based normalization (Mestdagh et al. 2009; Peltier and Latham 2008). Data driven invariant selection of miRNAs whose expression pattern is similar to the global mean expression (Mestdagh et al. 2009; Chang et al. 2010) has been suggested. Moreover, invariant selection based on a distinguishable low standard deviation and high-mean population as suggested by Pradervand et al. (2009) for miRNA microarray preprocessing is generally applicable for RT-qPCR profiling experiments as well. Basically, the use of more than one reference gene increases the accuracy of quantification compared to the use of a single reference gene (Vandesompele et al. 2002; Andersen et al. 2004).

Calculation of a plate normalizing factor for RT-qPCR based expression profiling platforms, a scaling method suggested by Wang (2009), uses the average of eight selected miRNA expression values from a descending sorted list (Wang 2009). Plate-normalizing factor normalization corresponds to an enlargement of percentile normalization and needs further validation by independent datasets prior to judge the robustness of this method.

For large scale microRNA expression profiling studies the mean expression value normalization outperformed the current normalization strategy that makes use of stable small RNA controls, such as e.g. snoRNAs proposed by manufacturers, in terms of better 
reduction of technical variation (Mestdagh et al. 2009). However, the selection of a limited number of miRNAs or small RNA controls that resemble the mean expression value can be successfully used for normalization in follow-up studies where only a limited number of miRNA molecules are profiled to allow a more accurate assessment of relevant biological variation from a miRNA RT-qPCR profiling experiment (Mestdagh et al. 2009; Chang et al. 2010).

\section{Normalization methods for miRNA microarray experiments}

The first miRNA microarray experiments were accompanied by either normalization using scaling to the median or even no normalization of miRNA data by applying background signal subtraction only (summarized in Hua et al. 2008 and Pradervand et al. 2009). Only recently, comparative studies on the relative performance of different normalization methods within a miRNA microarray platform have emphasized the need for evaluating and identifying appropriate normalization methods (Rao et al. 2008, Pradervand et al. 2009, Hua et al. 2008). Signal intensities of miRNA microarray experiments may be biased by differences in sample RNA preparation, dye labelling, hybridization and washing efficiency, peculiarities of print tip, spatial or hybridization specific effects or pre-amplification of extracted RNA. Thus, several different normalization approaches have been applied to decrease the introduced technical variance and to minimize over all variance. However, up to now there is no clear consensus about their relative performances (Pradervand et al. 2009).

MiRNA microarrays can be single-color or dual-color systems calling for different normalization approaches. Single-colour miRNA microarrays have been predominately used, while dual-colour hybridization systems are less frequently prevalent (Rao et al. 2008). Both can be observed with respect to intra-array normalization for the correction of dye effects and 
inter-array approaches for the balance of the distribution differences among experiments (Chiogna et al. 2009).

Certain transformation or scaling based methodologies currently used for large-scale genome arrays have been adapted to and modified for miRNA arrays. Of these methods e.g. quantile (Bolstad et al. 2003) and LOESS (reviewed in Steinhoff and Vingron 2006) normalization as well as scaling (e.g. Hua et al. 2008, Lopez-Romero et al. 2010) are based on two assumptions, i) only a small portion of spots is differentially expressed, and ii) differentially expressed spots are homogeneously distributed with respect to both, over- and under-expressed miRNAs (Risso et al. 2009). However, these assumptions could fail for miRNA platforms as they are printed with a relatively small number of selected sequences (Risso et al. 2009; Hua et al. 2008). Moreover, the number of expressed miRs in a given sample tends to be small (Sarkar et al. 2009). Hence, the proportion of those miRNAs that are differentially expressed (among those expressed at all) is much larger than that observed when profiling global mRNA expression (Sarkar et al. 2009). Thus, one needs to verify whether these assumptions hold true for the respective datasets. If necessary, one should choose e.g. a normalization method for which most algorithms make only the minimal assumption that there exists a set of miRNAs whose expression is constant like invariantbased normalization (Pradervand et al. 2009). Alternatively, a normalization method free of assumption ii) e.g. the majority of algorithms for variance stabilization normalization (Huber et al. 2002) or even an assumption free approach (Xiong et al. 2008) can be utilized instead.

Quantile nomalization is a transformation method originally proposed by Bolstad et al. (2003) for oligonucleotide arrays. It is now widely used for one-color miRNA microarrays as well and was confirmed as one of the most robust methods (Hua et al. 2008; Pradervand et al. 2009; Rao et al. 2008; Bargaje et al. 2010). Quantile normalization is an inter-array approach and equalizes the distributions of expression intensities across arrays. Thus, quantile normalization assumes that the overall distribution of signal intensity does not 
change. While this assumption likely holds true for the comparison of p53 overexpressing versus control cells (Pradervand et al. 2009) or even for brain-heart comparisons according to Rao et al. (Rao et al. 2008) where only $5 \%$ of miRNAs were differentially expressed, it may not hold true in case large numbers of miRNAs are differentially expressed in only one direction. Such cases may be e.g. knockouts of essential miRNA biogenesis proteins which lead to a dramatic reduction in steady state miRNA levels by blocking production of mature miRNAs (Rao et al. 2008).

Quantile normalization might be applicable to dual-labeled array data if red and green channel are treated as independent two single-labeled array data. On the contrary, if two single-labeled array data are considered as a dual-labeled data (Do and Choi 2006) a LOESS normalization may be used.

LOESS (Locally Weighted Regression and Smooting Scatterplots) normalizations and its variants (Rao et al. 2008; Hua et al. 2008; Risso et al. 2009) are widely preferred transformation based methods which use local regression via locally weighted scatter plot smooth. As outlier values can strongly influence the local regression curve it is advisable to introduce weights that penalize outliers. Local regression via LOESS uses a quadratic polynomial weighted regression function with Tukey's biweight function (reviewed in Steinhoff and Vingron 2006) of the log ratios Cy3/Cy5 on overall spot intensity Cy3*Cy5 (the LOESS smoother for the so called MA-plots) (Risso et al. 2009).

Hua et al. (2008) demonstrated that for two-channel technology print-tip LOESS performed most consistent of all the 15 normalization methods which they compared illustrating that miRNA microarrays manufactured by print technology have, in addition, systematic spatial bias with respect to each block. Print-tip LOESS normalizes each $M$ value by subtracting the corresponding value on the tip-group LOESS curve from the raw data (Hua et al. 2008). However, in a similar study, Sarkar et al. (2009) did not find significant differences between 
print-tip LOESS and other normalizations. Risso et al. (2009) proposed the non-parametric LOESSM normalization which scales the expression data on the global median expression rather than on zero. This modification relaxes the assumption of symmetry among up- and down-regulated genes (Risso et al. 2009) and it was shown that LOESSM, in case of absence of channel-effect, outperformed other normalization methods (Risso et al. 2009). Combined with Generalized Procrustes Analysis (GPA) - an assumption free inter-array normalization (Xiong et al. 2008) - results were even more improved.

In essence, LOESS normalization and its modified variants demonstrate the adaptability of this approach. In addition, LOESS normalizations emerged as being robust in the reduction of non-biological bias, and it has been shown that the combination of LOESS and GPA is able to outperform other individual techniques.

Variance stabilization normalization (VSN), an inter-array transformation method, has frequently been applied to microRNA data (Sarkar et al. 2009; Pradervand et al. 2009). VSN was developed for mRNA arrays and is based on a parameterized arsinh transformation instead of a logarithmic transformation that calibrates sample-to-sample variations and renders variance approximately independent of the mean intensity (Huber et al. 2002). Spike-in VSN normalization as described restricts the model fit to spike-in spots (Sarkar et al. 2009). Normalization intensities for all miRNAs are then obtained by applying the resulting transformation to all spots of interest on the array. Thus, reliable results can only be obtained for intensities within the range covered by the spike-in used. Moreover, the use of internal spike-ins can provide a reasonable metric for assessing the performance of different normalization schemes (Sarkar et al. 2009) or allow for absolute quantification of miRNA expression by microarrays (Bissels et al. 2009). Pradervand et al. (2009) developed a linear regression method to select non-changing miRNAs (invariants) and used these invariants to calculate VSN parameter (VSN-INV). The approach for selecting invariant miRNAs is particularly appropriate, if a significant fraction is expected to be differentially expressed since VSN used with default parameter settings assumes that most genes are not 
differentially expressed, whereas the invariant-based regression only assumes that a subpopulation of expressed genes does not change (Pradervand et al. 2009). Pradervand et al. (2009) drew the conclusion that VSN-INV and quantile normalization were the most robust normalization methods compared to VSN with default parameter or scaling. In general, one should note that VSN strongly affects the distribution of the large fraction of miRNAs whose expression is near or at background, resulting in the large increase of variability for those microRNAs (Pradervand et al. 2009).

Invariant-based methods, or positive control normalization using the signal of predefined and stably expressed housekeeping (reference) genes, such as small non-coding RNA, has been used for one- or two-channel miRNA microarray profiling as one of the first approaches to normalize mRNA gene microarray data (summarized in Hua et al. 2008 and Pradervand et al. 2009). In these applications, non differentially expressed genes are selected which occur in the same rank order on each chip (rank invariants). These latter, however, could imply truly differentially expressed candidates as invariant if they did not change rank position. Such a case is conceivable for miRNA microarrays as they have features ranging only in the hundreds. Thus, a miRNA may have a large difference in intensity without appreciably altering its rank order (Pradervand et al. 2009). Most commercially available miRNA microarrays do not have controls for endogenous RNAs that have been shown to be robustly invariant between various different tissue samples or conditions (Rao et al. 2008). To date, there is no consensus on the existence and reliability of reference gene miRNAs. The selection of reference genes to normalize miRNA levels depends on bioinformatic analysis of the respective data (as shown for mRNA Vandesompele et al. 2002; Andersen et al. 2004) and is otherwise still rather empirical due to the lack of robust reference miRNAs (Benes and Castoldi 2010), although a universal reference miRNA reagent set has been proposed (Sarkar et al. 2009).

Moreover, inter-platform and inter-laboratory meta-analyses identified constitutively expressed miRNAs across tissues (Bargaje et al. 2010). A mean of expression levels of a set 
of 16 microRNAs showing minimum variability was reasonably successful as a normalization factor for comparing datasets generated by the same platforms. However, normalization using constitutive microRNAs was ineffective when comparing bead-based and microarraybased datasets. In these cases quantile and Z-score normalization were both successful in transforming the data sets generating comparable means and scale (Bargaje et al. 2010).

By applying scaling methods like Z-score (Bargaje et al. 2010), mean, median (reviewed in Hua et al. 2008), or $75^{\text {th }}$ percentile (Lopez-Romero et al. 2010), one assumes that different sets of intensities differ by a constant global factor. These are only correct for 'global multiplicative effects' (reviewed in Steinhoff and Vingron 2006), since all raw intensity values are multiplied with one common (i.e. global) scaling factor. The Z-score provides a meancentered rank for the expression level in units of standard deviation. Z-scores thus provide an index of the expression level of the miRNA with respect to the cellular pool of miRNA. Unlike other normalization methods Z-scores are not influenced by the addition of new datasets allowing flexible cross-platform validation of miRNA microarray profiling experiments (Bargaje et al. 2010).

Recently, Wang et al. (2010) suggested the pre-evaluation of the overall miRNA expression pattern by a panel of miRNAs using RT-qPCR assays to build a logistic regression model based on these results. The personalized logistic regression model based on 29 miRNAs efficiently calibrated the variance across arrays and improved miRNA microarray discovery accuracy compared with different scaling methods, LOESS or quantile normalization (Wang et al. 2010). However, selection of the miRNAs included in pre-evaluations seems rather empirical. This personalized logistic regression model approach needs to be evaluated by further independent studies to estimate robustness of this normalization method. 


\section{Normalization techniques for small RNA-seq data}

An advantage of RNA-seq is that it can capture transcriptome dynamics without sophisticated normalization of data sets (Wang et al. 2009). This might hold true for direct RNA sequencing approaches (Ozsolak et al. 2009). At present, however, standard normalization methods for non-direct RNA-seq are not sufficient to remove RNA composition bias because relying on library size (Robinson and Oshlack 2010). Systematic technical bias such as RNA ligase preferences, reverse transcription reaction, and PCR based amplification during library preparation are likely to contribute to bias in RNA-seq experiments (Linsen et al. 2009).

Small RNA-seq approaches relying on cDNA library-construction are strongly biased towards certain small RNAs (Linsen et al. 2009) largely independent of the sequencing platform but strongly determined by the method used for small RNA library preparation. However, a satisfactory correction model has not yet been identified (Linsen et al. 2009). As these biases are systematic and highly reproducible (Marioni et al. 2008), RNA-seq may be suited for determining relative expression differences between samples (Linsen et al. 2009).

However, technical sample to sample variations may be introduced before and in follow-up steps of library preparation. Nevertheless, several small RNA-seq studies do not report on data normalization at all. Following microarray technology, quantile normalization of small RNA-seq data has been utilized to remove systematic bias between samples (Pradervand et al. 2010) and other normalization strategies established for microarrays could theoretically be applied as well.

At present, scaling to library size is the standard procedure to normalize small RNA-seq experiments. Using this method reads are divided by the total number of small RNA-seq reads aligning to the genome (Marques et al. 2010). Alternatively, the relative frequency of 
miRNAs is determined by normalizing miRNA reads against the total count of 18 to 22 nucleotide reads or total number of reads that map to known miRNAs, respectively (Zhang et al. 2009; Linsen et al. 2009; Git et al. 2010). Normalized data is then reported as reads (or transcripts) per million for each respective library. However, the problem underlying the analysis of RNA-seq data is that while the total number of reads for a library is known, the composition of the RNA population is unknown. Thus, library size scaling might have its limitations for datasets with markedly different RNA composition (Robinson and Oshlack 2010; Marques et al. 2010).

Only recently, trimmed mean of $\mathbf{M}$-values (TMM) normalization has been suggested to remove RNA composition bias as the number of reads for a gene is dependent not only on the gene's expression level and length, but also on the population of RNA from which it originates (Robinson and Oshlack 2010). RNA population differences like abundance or diversity of different small RNA species lead to a different distribution of available reads per gene and may skrew data. Therefore, TMM equates the overall expression levels of genes between samples by estimation of relative RNA production levels or scale factors, respectively, that can be incorporated into currently used statistical methods for differential expression analysis without modification of the sampling properties of the data itself. Similar to assumptions made in microarray normalization procedures such as LOESS or quantile normalization, TMM assumes that the majority of genes common to both samples, are not differentially expressed. Moreover, simulation studies indicate that the TMM method is robust against deviations to this assumption up to about $30 \%$ of differential expression in one direction (Robinson and Oshlack 2010). It can be expected that this assumption will not be violated for most small RNA-seq applications. Thus, independent utilization and evaluation of TMM normalization can be awaited in the near future. 


\section{Conclusions and perspectives}

Introducing normalization strategies to raw expression data is crucial for the reduction of false positives or negative data points. In many ways mRNA and miRNA experiments face similar influencing factors introducing bias. However, the nature of miRNA profiling data which mirrors the distinct biogenesis and physicochemical nature of miRNAs can challenge conventional normalization methods originally developed for mRNA expression data. Thus, several normalization methods have been adapted or proposed for miRNA expression profiling analyses.

Biological or experimental setups which are accompanied by significant global changes in miRNA amount or composition may not meet certain assumptions on data distribution, e.g. if miRNA biogenesis pathways are affected or very distinct tissues are compared. Thus, nonparametric or assumption free transformation methods and specific scaling approaches emerge as robust, frequently used methods in addition to parametric and linear normalization techniques. The combination of two normalization methods, that in each case handle different aspects of microarray data has been shown to be able to outperform other individual techniques in some cases (Risso et al. 2009; Pradervand et al. 2009). It is unlikely that a set of truly universal reference miRNAs will be identified, but similar to mRNA a subset of promising candidates will further emerge. The importance of validating suitable reference genes in a sample-specific context remains.

When novel miRNA discovery is not of priority, assumption based technologies can still be the method of choice as RT-qPCR and hybridization based microarrays still surpass RNAseq technology with respect to absolute RNA expression quantification. RNA-seq was shown to be strongly biased towards certain small RNAs. In contrary to microarrays, these shortcomings might not be overcome with the use of synthetic spike-in controls until a suitable correction model for sequence specific biases has been developed. Generally, evaluation of normalization methods is most in its infancy for RNA-seq, but has both a great potential and a challenging demand to be further optimized. 
In conclusion, there are many distinct ways to normalize miRNA expression profiling datasets ultimately leading to uncovering a layer of post-transcriptional regulatory complexity. Individual selection of the optimal normalization method, dependent on the characteristics of the dataset, can be strongly recommended. Standard normalization methods may carefully need to be scrutinized in specific biological contexts. It still remains unclear which method uniformly outperforms the others under different experimental setup - if there is any single approach fulfilling these demands at all. Evaluation of the goodness of a normalization method remains a challenge on its own. The reduction in the coefficient of variation as well as the concordance with good positive controls or inter-platform as well as inter-technology validations, respectively, measured as consistency of $p$-values or fold-changes, may serve as evaluation criteria. 


\section{References}

Andersen CL, Jensen JL, Orntoft TF (2004) Normalization of real-time quantitative reverse transcription-PCR data: a model-based variance estimation approach to identify genes suited for normalization, applied to bladder and colon cancer data sets. Cancer Res 64: 5245-5250

Baker M(2010) RNA interference: MicroRNAs as biomarkers. Nature 464: 1227

Bargaje R, Hariharan M, Scaria V, Pillai B (2010) Consensus miRNA expression profiles derived from interplatform normalization of microarray data. RNA 16: 16-25

Becker C, Hammerle-Fickinger A, Riedma ier I, Pfaffl MW (2010) mRNA and microRNA quality control for RT-qPCR analysis. Methods 50: 237-243

Benes V and Castoldi M (2010) Expression profiling of microRNA using real-time quantitative PCR, how to use it and what is available. Methods 50: 244-249

Beuvink I, Kolb FA, Budach W, Garnier A, Lange J, Natt F, Dengler U, Hall J, Filipowicz W, Weiler J (2007) A novel microarray approach reveals new tissue-specific signatures of known and predicted mammalian microRNAs. Nucleic Acids Res 35: e52

Bissels U, Wild S, Tomiuk S, Holste A, Hafner M, Tuschl T, Bosio A (2009) Absolute quantification of microRNAs by using a universal reference. RNA 15: 2375-2384

Bolstad BM, Irizarry RA, Astrand M, Speed TP (2003) A comparison of normalization methods for high density oligonucleotide array data based on variance and bias. Bioinformatics 19: 185193

Bustin SA (2010) Why the need for qPCR publication guidelines?--The case for MIQE. Methods 50: 217-226

Bustin SA, Benes V, Garson JA, Hellemans J, Huggett J, Kubista M, Mueller R, Nolan T, Pfaffl MW, Shipley GL, Vandesompele J, Wittwer CT (2009) The MIQE guide lines: minimum information for publication of quantitative real-time PCR experiments. Clin Chem 55: 611622

Cardinali B, Castellani L, Fasanaro P, Basso A, Alema S, Martelli F, Falcone G (2009) Microrna-221 and microrna-222 modulate differentiation and maturation of skeletal muscle cells. PLoS One 4: e7607

Carlsbecker A, Lee JY, Roberts CJ, Dettmer J, Lehesranta S, Zhou J, Lindgren O, Moreno-Risueno MA, Vaten A, Thitamadee S, Campilho A, Sebastian J, Bowman JL, Helariutta Y, Benfey PN (2010) Cell signalling by microRNA165/6 directs gene dose-dependent root cell fate. Nature 465: 316-321

Carthew RW and Sontheimer EJ (2009) Origins and Mechanisms of miRNAs and siRNAs. Cell 136: $642-655$ 
Castoldi M, Schmidt S, Benes V, Hentze MW, Muckenthaler MU (2008) miChip: an array-based method for microRNA expression profiling using locked nucleic acid capture probes. Nat Protoc 3: 321-329

Chang KH, Mestdagh P, Vandesompele J, Kerin MJ, Miller N (2010) MicroRNA expression profiling to identify and validate reference genes for relative quantification in colorectal cancer. BMC Cancer 10: 173

Chen C, Ridzon DA, Broomer AJ, Zhou Z, Lee DH, Nguyen JT, Barbisin M, Xu NL, Mahuvakar VR, Andersen MR, Lao KQ, Livak KJ, Guegler KJ (2005) Real-time quantification of microRNAs by stem-loop RT-PCR. Nucleic Acids Res 33: e179

Chiogna M, Massa MS, Risso D, Romualdi C (2009) A comparison on effects of normalisations in the detection of differentially expressed genes. BMC Bioinformatics 10:61

Do JH and Choi DK (2006) Normalization of microarray data: single-labeled and dual-labeled arrays. Mol Cells 22: 254-261

Fabian MR, Sonenberg N, Filipow icz W (2010) Regulation of mRNA translation and stability by microRNAs. Annu Rev Biochem 79: 351-379

Gangaraju VK and Lin H (2009) MicroRNAs: key regulators of stem cells. Nat Rev Mol Cell Biol 10: $116-125$

Git A, Dvinge H, Salmon-Divon M, Osborne M, Kutter C, Hadfield J, Bertone P, Caldas C (2010) Systematic comparison of microarray profiling, real-time PCR, and next-generation sequencing technologies for measuring differential microRNA expression. RNA 16: 991-1006

Griffiths-Jones S, Saini HK, van DS, Enright AJ (2008) miRBase: tools for microRNA genomics. Nucleic Acids Res 36: D154-D158

Gunaratne PH (2009) Embryonic stem cell microRNAs: defining factors in induced pluripotent (iPS) and cancer (CSC) stem cells? Curr Stem Cell Res Ther 4: 168-177

Hua YJ, Tu K, Tang ZY, Li YX, Xiao HS (2008) Comparison of normalization methods with microRNA microarray. Genomics 92: 122-128

Huber W, von HA, Sultmann H, Poustka A, Vingron M (2002) Variance stabilization applied to microarray data calibration and to the quantification of differential expression. Bioinformatics 18 Suppl 1: S96-104

Iliopoulos D, Malizos KN, Oikonomou P, Tsezou A (2008) Integrative microRNA and proteomic approaches identify novel osteoarthritis genes and their collaborative metabolic and inflammatory networks. PLoS One 3: e3740

Jayaswal V, Lutherborrow M, Ma DD, Hwa YY (2009) Identification of microRNAs with regulatory potential using a matched microRNA-mRNA time-course data. Nucleic Acids Res 37: e60

Kim JW, Mori S, Nevins JR (2010) Myc-induced microRNAs integrate Myc-mediated cell proliferation and cell fate. Cancer Res 70: 4820-4828 
Kong W, Zhao JJ, He L, Cheng JQ (2009) Strategies for profiling microRNA expression. J Cell Physiol 21 8: 22-25

Li W and Ruan K (2009) MicroRNA detection by microarray. Anal Bioanal Chem 394: 1117-1124

Liang Y, Ridzon D, Wong L, Chen C (2007) Characterization of microRNA expression profiles in normal human tissues. BMC Genomics 8: 166

Linsen SE, de WE, Janssens G, Heater S, Chapman L, Parkin RK, Fritz B, Wyman SK, de BE, Voest EE, Kuersten S, Tewari M, Cuppen E (2009) Limitations and possibilities of small RNA digital gene expression profiling. Nat Methods 6: 474-476

Lopez-Romero P, Gonzalez MA, Calle jas S, Dopazo A, Irizarry RA (2010) Processing of Agilent microRNA array data. BMC Res Notes 3: 18

Lu J, Getz G, Miska EA, varez-Saavedra E, Lamb J, Peck D, Sweet-Cordero A, Ebert BL, Mak RH, Ferrando AA, Downing JR, Jacks T, Horvitz HR, Golub TR (2005) MicroRNA expression profiles classify human cancers. Nature $435: 834-838$

Manakov SA, Grant SG, Enright AJ (2009) Reciprocal regulation of microRNA and mRNA profiles in neuronal deve lopment and synapse formation. BMC Genomics 10: 419

Marioni JC, Mason CE, Mane SM, Stephens M, Gilad Y (2008) RNA-seq: an assessment of technical reproducibility and comparison with gene expression arrays. Genome Res 18: 1509-1517

Marques JT, Kim K, Wu PH, Alleyne TM, Jafari N, Carthew RW (2010) Loqs and R2D2 act sequentially in the siRNA pathway in Drosophila. Nat Struct Mol Biol 17: 24-30

Mestdagh P, Van VP, De WA, Muth D, Westermann F, Speleman F, Vandesompele J (2009) A novel and universal method for microRNA RT-qPCR data normalization. Genome Biol 10: R64

Ozsolak F, Platt AR, Jones DR, Reifenberger JG, Sass LE, McInerney P, Thompson JF, Bowers J, Jarosz M, Milos PM (2009) Direct RNA sequencing. Nature 461: 814-818

Peltier HJ and Latham GJ (2008) Normalization of microRNA expression levels in quantitative RTPCR assays: identification of suitable reference RNA targets in normal and cancerous human solid tissues. RNA 14: 844-852

Pfaffl MW, Tichopad A, Prgomet C, Neuvians TP (2004) Determination of stable housekeeping genes, differentially regulated target genes and sample integrity: BestKeeper--Excel-based tool using pair-wise correlations. Biotechnol Lett 26: 509-515

Pfeifer A and Lehmann H (2010) Pharmacological potential of RNAi - focus on miRNA. Pharmacol Ther 126: 217-227

Pradervand S, Weber J, Lemoine F, Consales F, Paillusson A, Dupasquier M, Thomas J, Richter H, Kaessmann H, Beaudoing E, Hagenbuchle O, Harshman K (2010) Concordance among digital gene expression, microarrays, and qPCR when measuring differential expression of microRNAs. Biotechniques 48: 219-222 
Pradervand S, Weber J, Thomas J, Bueno M, Wirapati P, Lefort K, Dotto GP, Harshman K (2009) Impact of normalization on miRNA microarray expression profiling. RNA 15: 493-501

Rao Y, Lee Y, Jarjoura D, Ruppert AS, Liu CG, Hsu JC, Hagan JP (2008) A comparison of normalization techniques for microRNA microarray data. Stat Appl Genet Mol Biol 7: Article22

Risso D, Massa MS, Chiogna M, Romualdi C (2009) A modified LOESS normalization applied to microRNA arrays: a comparative evaluation. Bioinformatics 25: 2685-2691

Robinson MD and Oshlack A (2010) A scaling normalization method for differential expression analys is of RNA-seq data. Genome Biol 11: R25

Sarkar D, Parkin R, Wyman S, Bendoraite A, Sather C, Delrow J, Godwin AK, Drescher C, Huber W, Gentleman R, Tewari M (2009) Quality assessment and data analysis for microRNA expression arrays. Nucleic Acids Res 37: e17

Sato F, Tsuchiya S, Terasawa K, Tsujimoto G (2009) Intra-platform repeatability and inter-platform comparability of microRNA microarray technology. PLoS One 4: e5540

Sheng Y, Engstrom PG, Lenhard B (2007) Mammalian microRNA prediction through a support vector machine model of sequence and structure. PLoS One 2: e946

Steinhoff C and Vingron M (2006) Normalization and quantification of differential expression in gene expression microarrays. Brief Bioinform 7: 166-177

Vandesompele J, De PK, Pattyn F, Poppe B, Van RN, De PA, Speleman F (2002) Accurate normalization of real-time quantitative RT-PCR data by geometric averaging of multiple internal control genes. Genome Biol 3: RESEARCH0034

Vasudevan S, Tong Y, Steitz JA (2007) Switching from repression to activation: microRNAs can upregulate translation. Science 318: 1931-1934

Wang B, Wang XF, Howell P, Qian X, Huang K, Riker AI, Ju J, Xi Y (2010) A personalized microRNA microarray normalization method us ing a logistic regression model. Bioinformatics 26: 228-234

Wang H, Ach RA, Curry B (2007) Direct and sensitive miRNA profiling from low-input total RNA. RNA 13: 151-159

Wang V and Wu W (2009) MicroRNA-based therapeutics for cancer. BioDrugs 23: 15-23

Wang X (2009) A PCR-based platform for microRNA expression profiling studies. RNA 15: 716-723

Wang Z, Gerstein M, Snyder M (2009) RNA-Seq: a revolutionary tool for transcriptomics. Nat Rev Genet 10: 57-63 
Willenbrock H, Sa lomon J, Sokilde R, Barken KB, Hansen TN, Nielsen FC, Moller S, Litman T (2009) Quantitative miRNA expression analysis: comparing microarrays with next-generation sequencing. RNA 15: 2028-2034

Xiong H, Zhang D, Martyniuk CJ, Trudeau VL, Xia X (2008) Using generalized procrustes analysis (GPA) for normalization of cDNA microarray data. BMC Bioinformatics 9: 25

Yin JQ, Zhao RC, Morris KV (2008) Profiling microRNA expression with microarrays. Trends Biotechnol 26: 70-76

Zhang L, Chia JM, Kumari S, Ste in JC, Liu Z, Narechania A, Maher CA, Guill K, McMullen MD, Ware D (2009) A genome-wide characterization of microRNA genes in maize. PLoS Genet 5: e1000716 
Table 1: Basic summary of miRNA profiling by RT-qPCR, microarray and small RNAseq, including corresponding normalization methods. Each profiling approach has specific advantages and disadvantages which should be weighted depending on the research context. Aspects of consideration range from economic and time capacity issues to sample availability, required sensitivity and dynamic range, absolute or relative quantification, as well as the biological hypothesis to be tested. RT-qPCR has superior sensitivity (Chen et al. 2005) and requires low time expenditure. Microarray-based techniques have the advantage of being relatively cost-effective, relatively quick from RNA labeling to data generation and simple to use (Pradervand et al. 2010). Ultra high throughput DNA sequencing allows for the de novo detection and relative quantification of miRNAs, but requires a considerable amount of time for data generation and data analysis. The dynamic range of sequencing depends on the sequencing depth. 
Table 1

\begin{tabular}{|c|c|c|c|}
\hline & $\begin{array}{l}\text { microRNA } \\
\text { RT-qP CR }\end{array}$ & $\begin{array}{l}\text { microRNA } \\
\text { microarray }\end{array}$ & small RNA-seq \\
\hline Principle & PCR amplification & Hybridization & Sequencing \\
\hline Throughput & Medium to high & High & Ultra high \\
\hline Costs & economic & economic & comparatively high \\
\hline $\begin{array}{l}\text { Required amount } \\
\text { of RNA }\end{array}$ & $10 \mathrm{ng}-700 \mathrm{ng}$ & $100 \mathrm{ng}-10,000 \mathrm{ng}$ & $250 \mathrm{ng}-10,000 \mathrm{ng}$ \\
\hline Data generation & 1 day & $\begin{array}{l}\text { up to more than } \\
2 \text { days }\end{array}$ & $\begin{array}{l}\text { up to more than } \\
1 \text { week }\end{array}$ \\
\hline Limit of detection & $10^{-22} \mathrm{~mol}$ & $10^{-15}-10^{-18} \mathrm{~mol}$ & $10^{-15} \mathrm{~mol}$ \\
\hline Dynamic range & $10^{6}$ & $10^{3}-10^{4}$ & $10^{4}-10^{\prime}$ \\
\hline Data information & $\begin{array}{l}\text { Assumption based; } \\
\text { dependent on the } \\
\text { number and nature } \\
\text { of targeted } \\
\text { transcripts }\end{array}$ & $\begin{array}{l}\text { Assumption based; } \\
\text { dependent on the } \\
\text { number and nature } \\
\text { of targeted } \\
\text { transcripts }\end{array}$ & $\begin{array}{l}\text { Assumption free, de } \\
\text { novo identification of } \\
\text { transcripts within the } \\
\text { small RNA } \\
\text { transcriptome }\end{array}$ \\
\hline Data analysis & $\begin{array}{l}\text { Low } \\
\text { expenditure of time }\end{array}$ & $\begin{array}{l}\text { Moderate } \\
\text { expenditure of time }\end{array}$ & $\begin{array}{l}\text { Considerable } \\
\text { expenditure of time }\end{array}$ \\
\hline $\begin{array}{l}\text { Memory capacity } \\
\text { requirements }\end{array}$ & Low & Low & High \\
\hline $\begin{array}{l}\text { Preferential field } \\
\text { of application }\end{array}$ & $\begin{array}{l}\text { Relative and } \\
\text { absolute } \\
\text { quantification; } \\
\text { validation of other } \\
\text { miRNA profiling } \\
\text { approaches }\end{array}$ & $\begin{array}{l}\text { Relative and } \\
\text { absolute } \\
\text { quantification of } \\
\text { miRNA regulation, } \\
\text { miRNA biomarker } \\
\text { identification, routine } \\
\text { application and } \\
\text { higher throughput } \\
\text { with respect to } \\
\text { sample number } \\
\text { compared to small } \\
\text { RNA-seq }\end{array}$ & $\begin{array}{l}\text { De novo identification } \\
\text { of small RNAs, } \\
\text { simultaneous relative } \\
\text { quantification of } \\
\text { different small RNA } \\
\text { species, holistic } \\
\text { picture of the small } \\
\text { RNA transcriptome }\end{array}$ \\
\hline \multirow[t]{5}{*}{$\begin{array}{l}\text { Common } \\
\text { normalization } \\
\text { strategies }\end{array}$} & $\begin{array}{l}\text { Invariant-based (e.g. } \\
\text { stable reference } \\
\text { small non-coding } \\
\text { RNAs) }\end{array}$ & $\begin{array}{l}\text { Quantile } \\
\text { LOESS }\end{array}$ & $\begin{array}{l}\text { Scaling to library or } \\
\text { sub-library (e.g. } \\
\text { miRNA) size }\end{array}$ \\
\hline & Plate normalizing & Variance stabilization & Quantile \\
\hline & factor & Invariant-bas ed & $\begin{array}{l}\text { Trimmed mean of } \mathrm{M} \text { - } \\
\text { values }\end{array}$ \\
\hline & $\begin{array}{l}\text { Global mean } \\
\text { expression }\end{array}$ & $\begin{array}{l}\text { Scaling (e.g. Z-score, } \\
\text { mean, median, } 75^{\text {th }} \\
\text { percentile) }\end{array}$ & \\
\hline & & $\begin{array}{l}\text { Personalized logistic } \\
\text { regression model }\end{array}$ & \\
\hline
\end{tabular}


Table 2: MicroRNAs, small nuclear and small nucleolar RNAs suggested as stable reference genes for normalization of microRNA expression analyses. Reference RNAs identified by studies comparing different human or mouse tissues or cell lines, respectively, are listed. However, careful selection and analysis of the suitability of the respective microRNAs, small nuclear or small nucleolar RNAs as stable reference genes can strongly be recommended for each individual experimental setup. 


\begin{tabular}{|c|c|}
\hline $\begin{array}{l}\text { microRNA suggested as stable } \\
\text { reference gene in human and } \\
\text { mouse samples, respectively }\end{array}$ & $\begin{array}{l}\text { Studies comparing different } \\
\text { tissues or cell lines which suggest } \\
\text { the respective microRNA }\end{array}$ \\
\hline hsa-miR-103 & $\begin{array}{l}\text { (Lia ng et al. 2007); (Peltier and La tha } m \\
\text { 2008); (Ba rgaje et al. 2010) }\end{array}$ \\
\hline hsa-miR-105 & (Bargaje et al. 2010) \\
\hline hsa-miR-106a & (Pel tierand La tha $m$ 2008) \\
\hline hsa-miR-106b & (Liang et al. 2007) \\
\hline hsa-miR-107 & (Ba rgaje et al. 2010) \\
\hline hsa-miR-139 & (Ba rgaje et al. 2010) \\
\hline hsa-miR-140 & (Liang et al. 2007) \\
\hline hsa-miR-148a & (Bargaje et al. 2010) \\
\hline hsa-miR-152N & (Liang et al. 2007) \\
\hline hsa-miR-15b & (Liang et al. 2007) \\
\hline hsa-miR-16 & $\begin{array}{l}\text { (Liang et al. 2007); (Peltier and La tha m } \\
\text { 2008); (Applied Biosys tems*) }\end{array}$ \\
\hline hsa-miR-17-5p & (Pel tie rand La tha $m$ 2008) \\
\hline hsa-miR-183 & (Ba rgaje et al. 2010) \\
\hline hsa-miR-18a & (Bargaje et al. 2010) \\
\hline hsa-miR-191 & $\begin{array}{l}\text { (Ba rgaje et al. 2010); (Pel tier and La tham } \\
\text { 2008) }\end{array}$ \\
\hline hsa-miR-213 & (Bargaje et al. 2010) \\
\hline hsa-miR-214 & (Bargaje et al. 2010) \\
\hline hsa-miR-23a & (Ba rgaje et al. 2010) \\
\hline hsa-miR-23b & (Ba rgaje et al. 2010) \\
\hline hsa-miR-24 & (Pel tierand La tha $m$ 2008) \\
\hline hsa-miR-25 & (Pel tierand La tha $m$ 2008) \\
\hline hsa-miR-26a & (Ba rgaje et al. 2010) \\
\hline hsa-miR-26b & (Ba rgaje et al. 2010); (Applied Bios ys te ms) \\
\hline hsa-miR-29a & (Liang et al. 2007) \\
\hline hsa-miR-29a N & (Liang et al. 2007) \\
\hline hsa-miR-29bN & (Liang et al. 2007) \\
\hline hsa-miR-30b & (Bargaje et al. 2010) \\
\hline hsa-miR-30d & (Bargaje et al. 2010) \\
\hline hsa-miR-30e & (Liang et al. 2007) \\
\hline hsa-miR-324-3p & (Liang et al. 2007) \\
\hline hsa-miR-374 & (Applied Biosys te ms ) \\
\hline hsa-miR-423 & (Liang et al. 2007) \\
\hline hsa-miR-423 & (Applied Biosys tems*) \\
\hline hsa-miR-92 & $\begin{array}{l}\text { (Liang et al. 2007); (Ba rga je et al. 2010); } \\
\text { (Applied Bios ys tems*) }\end{array}$ \\
\hline hsa-miR-92N & (Liang et al. 2007); (Applied Biosys tems*) \\
\hline hsa-miR-93 & $\begin{array}{l}\text { (Liang et al. 2007); (Barga je et al. 2010); } \\
\text { (Peltierand La tha } \mathrm{m} \text { 2008) }\end{array}$ \\
\hline $\begin{array}{l}\text { hsa-miR-99a } \\
\text { hsa-let-7a }\end{array}$ & $\begin{array}{l}\text { (Peltierand La tha } m \text { 2008) } \\
\text { (Pel tierand La tha } m \text { 2008) }\end{array}$ \\
\hline $\begin{array}{l}\text { Small nuclear and small } \\
\text { nucleolar RNAs suggested as } \\
\text { stable reference gene in human } \\
\text { and mouse, respectively }\end{array}$ & $\begin{array}{l}\text { Comparison across tissues and cell } \\
\text { lines suggesting the respective } \\
\text { small nuclear or small nucleolar } \\
\text { RNA }\end{array}$ \\
\hline RNU44 & (Applied Bios ys tems*) \\
\hline RNU48 & (Applied Biosys te ms*) \\
\hline U47 & (Applied Biosys tems*) \\
\hline RNU6B & (Applied Biosys te ms*) \\
\hline snoRNA202 & (Applied Biosys tems*) \\
\hline snoRNA234 & (Applied Biosys te ms*) \\
\hline
\end{tabular}

*Applied Bios ystems: Endogenous controls for real-time quantification of miRNA using TaqMan microRNA assays. (ed. Application Note). 